Notas de Pesquisa

Research Notes

\title{
Percepção dos alunos do Colégio Militar de Brasília sobre a inserção de novos conteúdos de Lutas na Educação Física Escolar: um estudo exploratório
}

\section{Perception of Students from Military School of Brasília about the Insertion of New Content of Fighting Sports in Physical Education Classes: An Exploratory Study}

João Batista de Andrade Neto ${ }^{\S 1} \mathrm{MSc}$; Gabriel Moreira Pereira ${ }^{2}$

Recebido em: 07 de junho de 2021. Aceito em: 19 de julho de 2021.

Publicado online em: 14 de setembro de 2021.

DOI: $10.37310 /$ ref.v90i2.2764

\section{Resumo}

Introdução: A inclusão de novos conteúdos de Lutas na educação física escolar é uma crescente demanda do Colégio Militar de Brasília (CMB)e a diversificação desses conteúdos pode potencialmente incentivar o trato pedagógico de forma holística, contemplando integralmente a abordagem do "Ensino por Competências". Objetivo: Realizar um levantamento exploratório acerca da percepção dos alunos do CMB sobre a inserção de novos conteúdos de Lutas na Educação Física Escolar.

Métodos: Este estudo foi do tipo descritivo quantitativo exploratório, em amostragem do tipo censo, com a participação de 1.021 alunos voluntários, de ambos os sexos, idade entre 10 e 18 anos, com aplicação de um questionário semiestruturado, por meio do Ambiente Virtual de Aprendizagem, no período de julho a dezembro de 2020.

Resultados: As Lutas são as atividades físicas preferidas

Pontos-Chave Destaque

- Todos os alunos do CMB já participavam de escolinhas de Lutas (atividade física extraclasse).

- A maioria indicou querer praticar Lutas no ambiente escolar.

- As três modalidades mais indicadas foram Krav Maga, Karatê e Taekwondô. dos alunos do CMB, quando comparadas as outras atividades físicas elencadas. As modalidades com maior interesse foram: o Krav Maga 30\%, Karatê 20\%, Taekwondô 10\%, Jiu Jitsu 10\%, Esgrima 10\%, Muay Tay $10 \%$, Capoeira, Judô, com $0,5 \%$ das intenções cada. Ainda, os principais objetivos apontados pelos participantes do estudo para a prática das Lutas foram: defesa pessoal, promoção da saúde e a participação em competições.

Conclusão: A maioria dos alunos do CMB já participa de escolinhas de Lutas no ambiente externo (espaço não formal de ensino). Contudo, desejam praticar essas modalidades, se ofertadas, no ambiente escolar (espaço formal de ensino). Houve uma maior indicação para a prática das modalidades de Krav Maga, Karatê e Taekwondô. Os interesses evidenciados foram a defesa pessoal, prática de atividade física e a participação em competições. As quais, se oportunizadas irão contemplar integralmente a metodologia do Ensino por Competências.

Palavras-chave: educação física escolar, Lutas, atividade física, percepção, ensino por competências.

${ }^{\S}$ Autor correspondente: João Batista de Andrade Neto - e-mail: andradeneto@usp.br

Afiliações: ${ }^{1}$ Universidade de São Paulo-USP, Programa de Pós-graduação em Ciências da Saúde aplicadas ao Aparelho Locomotor, Faculdade de Medicina de Ribeirão Preto - SP; ${ }^{2}$ Universidade Federal do Maranhão-UFMA, Curso de Bacharel em Educação Física. 


\begin{abstract}
Introduction: The inclusion of new fighting sports in the content of the Physical Education classes is a growing demand of Brasília Military School (BMS) students. Thus, the diversification of these contents can encourage the pedagogical approach form a holistic perspective, fully contemplating the teaching by skills approach.

Objective: To carry out an exploratory survey about the perception of students from the BMS about the insertion of new contents of fighting sports in Physical Education classes. Methods: This was an exploratory quantitative descriptive study, with the participation of 1,021 volunteer students, of both genders, aged between 10 and 18 years, in which there was applied a semi-structured questionnaire, through the Virtual Learning Environment, from July to December 2020.

Results: Fights are the preferred physical activities of

\begin{tabular}{|l|}
\hline Keypoints \\
- All students that participated \\
in the studty participate in fight \\
extra-classes activities. \\
- The majority indicated \\
wanting to practice Fighting in \\
the school environment. \\
- The three most pointed out \\
modalities were Krav Maga, \\
Karate and Taekwondô. \\
\hline
\end{tabular}
students at Brasília Military College, when compared to other physical activities listed. The modalities with the greatest interest were: Krav Maga 30\%, Karate 20\%, Taekwondo 10\%, Jiu Jitsu 10\%, Fencing 10\%, Muay Tay 10\%, Capoeira, Judo, with $0.5 \%$ of the intentions each. Still, the main objectives pointed out by the study participants for the practice of fights were selfdefense, health promotion and participation in competitions.

Conclusion: Most students at the Brasília Military College already participate in fighting sports outside the school environment (extra class activities) and they would like to practice those modalities, if offered, at the physical education classes at the school. There was a greater indication for the practice of the modalities of Krav Maga, Karate and Taekwondo. The interests shown were self-defense, physical activity, and participation in competitions. Which, if given the opportunity, will fully contemplate the methodology of Competency-based Education.
\end{abstract}

Keywords: school physical education, fights, physical activity, perception, competency-based education.

\title{
Percepção dos alunos do Colégio Militar de Brasília sobre a inserção de novos conteúdos de Lutas na Educação Física Escolar: um estudo exploratório
}

\section{Introdução}

A inclusão do conteúdo de Lutas na educação física escolar há muito tempo é discutida pela literatura científica, bem como referenciada em documentos oficiais brasileiros, como os Parâmetros Curriculares Nacionais, Base Nacional Comum Curricular e Diretrizes Curriculares de vários Estados(1).

Consideradas parte do objeto de estudo da cultura corporal do movimento, as Lutas são produções humanas repletas de significados, que foram construídos historicamente e que possuem relações com as sociedades nas quais estão inseridas, sendo, dessa forma, um conteúdo significativo a ser abordado na escola $(2,3)$.
Entende-se que o trato pedagógico do conteúdo Lutas na Educação Física Escolar visa permitir aspectos como autonomia, emancipação, criticidade e a construção de conhecimentos. As reflexões que apontam a cultura corporal do movimento como tema da Educação Física no Ensino Básico munem, pedagogicamente, a construção de possibilidades para sua inserção no ambiente escolar(4,5).

O conteúdo Lutas também é considerado um eixo estruturante da Educação Física Escolar, agrupando um conjunto de conhecimentos e oportunidades que contribuem para o desenvolvimento integral do educando(5). Se respeitado o seu potencial pedagógico, é um instrumento valoroso nas mãos do educador, por sua 
ação corporal exclusiva, sua natureza histórica e o enorme acervo cultural que traz dos seus povos de origem(6).

Considerando a abordagem do Ensino por Competências adotada pelo Sistema de Ensino do Exército, a Diretoria de Educação Preparatória e Assistencial (DEPA), responsável pela coordenação e supervisão desses procedimentos junto ao Sistema Colégio Militar do Brasil, elabora anualmente currículos e documentos que dão suporte à prática docente, dentre eles os Projeto Pedagógico do Sistema Colégio Militar e o Plano de Execução Didática, o qual, na sua versão 2020, contempla somente três modalidades de Lutas: esgrima, capoeira e judô(7).

Atualmente, no Colégio Militar de Brasília (CMB), apenas o judô é ofertado como prática de Lutas. Sendo assim, atento à importância de dinamizar e otimizar o tempo e os espaços disponíveis do CMB para as práticas de Lutas, bem como pensando em um ensino holístico deste conteúdo conforme legislação nacional para educação básica, foi proposto, em 2020, o "Projeto Lutas CMB" à Divisão de Ensino e ao Corpo de Alunos, sugerindo a implantação de novas modalidades de Lutas, que, por sua natureza e classificação, são caracterizadas Lutas que mantêm distância(5), como parte integrante do currículo pedagógico na educação física escolar.

Em função da escassez literária sobre o tema, a necessidade de se verificar o interesse dos alunos na oferta de novas modalidades de Lutas a fim melhorar a prática do exercício físico no ambiente escolar. Este trabalho teve como objetivo, realizar um levantamento da percepção dos alunos do CMB sobre a inserção de novos conteúdos de Lutas na Educação Física Escolar.

\section{Métodos}

\section{Desenho de estudo e amostra}

Trata-se de uma pesquisa com delineamento metodológico descritivo quantitativo e exploratório, por meio da qual se procurou observar, registrar, analisar e correlacionar fenômenos, sem sua manipulação (8). Por se tratar de estudo exploratório, não foram estabelecidas hipóteses; os dados utilizados foram primários, e obtidos a partir da aplicação de questionário eletrônico semiestruturado disponibilizado pela plataforma Google Forms e enviado a 2.900 mil alunos por meio do Ambiente Virtual de Aprendizagem - AVA do próprio CMB. A amostra intencional foi composta por 1.021 alunos, de ambos os sexos, com idades entre 10 e 18 anos, matriculados no letivo de 2020 no CMB. Os dados foram coletados nos meses de julho a dezembro de 2020, período em que o CMB disponibilizava aulas de forma remota e presenciais alternadamente (hibridas), em razão da pandemia da COVID-19.

$\mathrm{O}$ instrumento usado na pesquisa foi um questionário semiestruturado com base no modelo descrito na literatura(9). O questionário é um método validado cientificamente, composto de um conjunto de perguntas ordenadas de acordo com um critério predeterminado, que pode e deve ser respondido sem a presença do entrevistador $(8,9)$. Os tópicos iniciais da entrevista foram pré-estabelecidos com base na percepção exploratória de estudos que abordaram o tema em questão.

As questões estabelecidas para os pesquisados foram: Questão 1: "Você pratica alguma atividade física de forma regular fora do CMB? Se sim, descreva quais Qual/Quais?; Questão 2: "Você teria interesse em praticar novas modalidades de Lutas durante as aulas de Educação Física no CMB?" Caso afirmativo, dentre as opções abaixo marque a de maior interesse; e Questão 3: "Dentre os objetivos abaixo descritos, qual o que mais se aproxima dos seus, caso venha praticar uma destas modalidades de Lutas no CMB? ". A versão completa do questionário apresenta-se no Anexo 1.

\section{Aspectos éticos}

Este estudo foi previamente aprovado pelo Comitê de Ética e Pesquisa da Escola de Educação Física e Esporte de Ribeirão Preto da USP, registro CAAE: 40025420.7.0000.5659, com parecer $\mathrm{n}^{\mathrm{o}}$ 
4.579.829, bem como pelo Diretor de Ensino do CMB. Todos os participantes e responsáveis foram orientados quanto aos procedimentos da pesquisa e assinaram o Termo de Assentimento Livre Esclarecido (TALE), quando menores de 18 anos, conforme a resolução 196/96 do Conselho Nacional de Saúde.

\section{Análise estatística}

Os dados obtidos foram submetidos a um tratamento prioritariamente quantitativo, com análise estatística quanto às frequências relativas das respostas.

\section{Resultados}

Participaram do estudo 1.021 alunos de ambos os sexos do CMB, sendo 428 (41,92\%) do Ensino Fundamental: 227 $(53,07 \%)$ do sexo masculino e 201 $(46,96 \%)$ do sexo feminino, com idades variando entre 10 e 13 anos); e 593 (58,08\%) do Ensino Médio: 170 (28,67\%) do sexo masculino e 423 (71,33\%) do sexo feminino, com idades variando entre 14 e 18 anos).

As práticas regulares de atividades físicas fora do ambiente escolar (atividades extraclasse) estão dispostas na Tabela 1. O tipo de atividade física com maior frequência relatada foi Lutas $(33,4 \%)$, seguido de corridas e caminhadas $(17,6 \%)$.

Os dados dispostos na Tabela 2, representam os achados da segunda questão, sobre quais modalidades de Lutas o(a) aluno(a) gostaria de praticar nas aulas de educação física escolar do CMB. O Krav Maga foi a modalidade de maior interesse relatado pelos participantes $(30,0 \%)$, seguida do Karatê $(20,0 \%)$.

$\mathrm{Na}$ Tabela 3, são apresentados os principais objetivos dos alunos para prática de modalidades de Lutas no ambiente escolar.

\section{Discussão}

O presente estudo apresentou um levantamento da percepção dos alunos do CMB sobre a inserção de novos conteúdos de Lutas na Educação Física Escolar.

Um primeiro aspecto observado foi o grau de interesse dos alunos pelo conteúdo pesquisado, pois, dos 2.900 questionários distribuídos, 1.021 retornaram respondidos mesmo em período de aulas híbridas, correspondendo a $51,05 \%$ dos matriculados no ano letivo de 2020, taxa de resposta considerada muito boa para estudos na área de gestão / administração(10). E ainda, a ampla adesão a prática de atividades físicas fora do ambiente escolar $100 \%$, bem como a participação do público feminino com $51,12 \%$ das respostas.

De acordo com os dados dispostos na Tabela 1, pode-se observar grande participação dos alunos pesquisados em atividades físicas fora do ambiente educacional (espaço não formal) para ambos os sexos. Dentre as atividades preferidas de forma ordenada, estão: Lutas, com 33,4\% das indicações, seguidas de musculação $15,0 \%$, corridas e caminhadas $13,1 \%$, futebol $9,6 \%$; ballet, $8,1 \%$ e $3,2 \%$ responderam praticar outras atividades não descritas no questionário.

A partir desses resultados, pode-se depreender que as Lutas são o conteúdo que os alunos mais apreciam, embora haja pouca ou quase nenhuma oferta no Sistema Colégio Militar do Brasil, tal como é apontado no PED de 2020(7), dado o universo de modalidades de Lutas disponíveis.

Tais resultados se assemelham aos divulgados na última Pesquisa Nacional por Amostra de Domicílios (PNAD) referente à prática de algum esporte ou atividade física, a qual evidenciou que $70,0 \%$ da população brasileira acima dos 15 anos de idade, praticaram ou praticam algum tipo de Lutas, artes marciais ou modalidades esportivas de combate(11).

A Tabela 02, faz alusão ao interesse dos alunos por novas modalidades de Lutas na educação física escolar do CMB: Jiu Jitsu com $10 \%$ do total das intenções, Esgrima $10 \%$ (atualmente esta modalidade não é ofertada), Muay Thay $0,5 \%$, Capoeira 0,5\%, Taekwondô $10 \%$, Karatê $20 \%$, Krav Maga $30 \%$, Judô $0,5 \%$, além de outras modalidades não descritas com $0,5 \%$ marcações. Observando os dados levantados, verificou-se maior interesse pe- 
Tabela 1 - Práticas regulares de atividades físicas extraclasse $(n=1.021)$

\begin{tabular}{lcccc}
\hline Variáveis & $\begin{array}{c}\text { Geral } \\
\text { (n) }\end{array}$ & $\begin{array}{c}\text { Masculino } \\
\text { (n) }\end{array}$ & $\begin{array}{c}\text { Feminino } \\
\text { (n) }\end{array}$ & $\begin{array}{c}\text { Frequência Relativa } \\
\text { (\%) }\end{array}$ \\
\hline \hline $\begin{array}{l}\text { Prática de atividade física } \\
\text { extraclasse }\end{array}$ & & & & \\
$\quad$ Sim & 1.021 & 499 & 522 & 100,0 \\
Não & 0 & 0 & 0 & 0,0 \\
Tipos de atividade física & & & & \\
Corridas/Caminhadas & 180 & 91 & 89 & 17,6 \\
Natação & 134 & 59 & 75 & 13,1 \\
Futebol & 98 & 90 & 8 & 9,6 \\
Musculação & 153 & 80 & 73 & 15,0 \\
Ballet & 83 & 2 & 80 & 8,1 \\
Lutas & 341 & 152 & 189 & 33,4 \\
Outras & 32 & 25 & 8 & 3,2 \\
\hline
\end{tabular}

Tabela 2 - Interesse por novas modalidades de Lutas na educação física $(\mathrm{n}=1.021)$

\begin{tabular}{lcccc} 
Variáveis & $\begin{array}{c}\text { Geral } \\
(\mathbf{n})\end{array}$ & $\begin{array}{c}\text { Masculino } \\
(\mathbf{n})\end{array}$ & $\begin{array}{c}\text { Feminino } \\
(\mathbf{n})\end{array}$ & $\begin{array}{c}\text { Frequência Relativa } \\
(\%)\end{array}$ \\
\hline Jiu Jitsu & 89 & 55 & 34 & 10,0 \\
Esgrima & 88 & 75 & 13 & 10,0 \\
Muay Thay & 76 & 36 & 40 & 0,5 \\
Capoeira & 67 & 45 & 22 & 0,5 \\
Taekwondô & 108 & 61 & 47 & 10,0 \\
Karatê & 199 & 85 & 114 & 20,0 \\
Krav Maga & 293 & 95 & 198 & 30,0 \\
Judô & 45 & 20 & 25 & 0,5 \\
Outras & 56 & 27 & 29 & 0,5 \\
\hline
\end{tabular}

Tabela 3 - Objetivos dos alunos para a prática de Lutas na educação física escolar $(\mathrm{n}=1.021)$

\begin{tabular}{lcccc}
\hline Variáveis & Geral & Masculino & Feminino & $\begin{array}{c}\text { Frequência } \\
\text { Relativa (\%) }\end{array}$ \\
\hline $\begin{array}{l}\text { Participar de } \\
\text { competições }\end{array}$ & 253 & 199 & 54 & 25,0 \\
Aprender defesa & & & & \\
pessoal & 406 & 205 & 201 & 40,0 \\
Benefícios à saúde & 309 & 189 & 120 & 30,0 \\
Outros & 53 & 31 & 22 & 5,0 \\
\hline
\end{tabular}


las modalidades de Taekwondô e Karatê, ambas modalidades esportivas de combate com status olímpico, e pelo Krav Maga, um método de defesa pessoal criado em Israel, considerado atualmente a modalidade de luta em maior ascensão no Brasil(12).

$\mathrm{O}$ que realmente torna as Lutas um componente fundamental para o currículo de Educação Física é a sua variedade de elementos e movimentos, muitas vezes diferentes daqueles conhecidos pelo aluno $(13,14)$. Esta proximidade com o novo, além de ser altamente motivante pelo desafio que proporciona à necessidade de ação do aluno, despertando o prazer no encontro com o desconhecido, é acrescida pelo contato que o discente tem com outras culturas, diferentes da qual ele está inserido, aumentando o seu conhecimento de mundo(4,5,13).

Ao se meditar sobre o tema escolinhas de esportes, verifica-se que os autores que a estudam indicam a iniciação esportiva como uma forma de detecção e formação de talentos para o esporte. Contudo, seu principal objetivo deve ser a formação socioeducativa e do caráter do futuro cidadão, considerando o desenvolvimento integral da criança nos aspectos motores, cognitivos, emocional e social, preparando assim seus praticantes para a cidadania e para o lazer, plenamente contemplados pelo conteúdo de Lutas(14).

Dentre os objetivos para a prática de Lutas na educação física descritos na Tabela 3 , verificou-se que os entrevistados buscam principalmente ganhos de conhecimento sobre como aprender a se defender $(40 \%)$, seguidos dos benefícios à saúde promovidos pela prática das modalidades de Lutas como atividade física (30\%). Buscam, ainda, ingressar em competições esportivas, totalizando $25 \%$. Outros objetivos não especificados obtiveram $5 \%$ das intenções, conforme demonstrado em valores percentuais.

Considerando o Projeto Pedagógico do Sistema Colégio Militar do Brasil, com ênfase no "Ensino por Competências", a ação recebe mais ênfase, à medida em que a escola parte ao encontro das motivações e conhecimentos prévios dos alunos, em detrimento de conceitos previamente estabelecidos, para fazê-los encontrar um significado nos conteúdos(7).

Neste sentido, o conhecimento e a aprendizagem de novas modalidades de Lutas de forma integral poderão oportunizar maior clareza aos alunos, pois passarão a se sentir mais motivados ao identificar a finalidade do que estão aprendendo e, ainda, terão suas expectativas atendidas pelo Colégio Militar de Brasília.

A seleção de novos conteúdos de Lutas e sua aplicação na Educação Física Escolar, deve comtemplar de forma integral a compreensão da cultural corporal. (1) Para tanto, é consenso na literatura que deve se basear em três diferentes critérios: relevância social a qual, justifica-se com a prática de atividades contemporâneas e marcantes na sociedade brasileira, o que promoverá maior iteração sociocultural dos alunos); características dos alunos, respeitadas as diferenças regionais, crescimento e desenvolvimento maturacional, e as especificidades do conhecimento da área e o tratamento metodológico do conteúdo(1-5).

Assim, entende-se que será garantido aos estudantes oportunidades de compreensão, apreciação e produção de Lutas e práticas corporais, estimulando o compartilhamento de valores, condutas e emoções; a percepção das marcas identitárias e a desconstrução de preconceitos e estereótipos, a reflexão crítica a respeito das relações práticas corporais, mídia e consumo, como também quanto a padrões de beleza, exercício, desempenho físico e saúde são as mais importantes funções das Lutas(11-16).

\section{Pontos fortes e limitações do estudo}

O presente estudo apresentou resultados de pesquisa quanto à pratica de lutas no $\mathrm{CMB}$, o que foi inédito. A relevância fica destacada por representar uma busca aos interesses dos alunos visando motivar a aderência às práticas esportivas.

Uma limitação foi que cerca de $49 \%$ não respondeu à pesquisa. Apesar disso, a taxa de respostas de $51 \%$ é considerada boa para estudos na área de Gestão/Administração. 


\section{Conclusão}

Os principais achados no presente estudo foram que a maioria dos alunos do CMB já participa de escolinhas de Lutas no ambiente externo (espaço não formal de ensino). No entanto, desejam praticar essas modalidades, se ofertadas, no ambiente escolar (espaço formal de ensino). Houve uma maior indicação para a prática das modalidades Krav Maga, Karatê, Taekwondô, Muay Thay, Capoeira, Judô e outras não listadas.

Ao apreciar os objetivos dos alunos para a prática de Lutas, os resultados apontaram um grande interesse por defesa pessoal, para os benefícios de sua prática para a saúde e a participação em competições. Essas intenções, poderiam ser plenamente contempladas pelas modalidades apontadas como preferidas, pois suas características compreendem de forma holística essas expectativas.

Nesse sentido, considerando a literatura disponível, a implantação de novos conteúdos de Lutas pode vir a atender integralmente as diversas demandas sociais, fisiológicas, psicológicas, educacionais e esportivas dos discentes, contemplando positivamente à metodologia do ensino por competências, tão defendida e difundida pelo Sistema de Ensino do Exército. No entanto, vale ressaltar que novos estudos mais aprofundados nas mais variadas áreas de conhecimento se fazem necessários e urgentes, dada a relevância do tema Lutas na sociedade contemporânea.

\section{Agradecimentos}

À Divisão de Ensino, ao Corpo de Alunos e ao Comando do $\mathrm{CMB}$, que possibilitaram a realização desta pesquisa, e a todos os participantes, que gentilmente cederam seus dados para elaboração deste importante instrumento de diagnóstico.

\section{Declaração de conflito de interesses}

Não há nenhum conflito de interesses em relação ao presente estudo.

\section{Declaração de financiamento}

Estudo realizado sem financiamento.

\section{Referências}

1. Rufino LGB; Darido SC. Possíveis diálogos entre a educação física escolar e o conteúdo das Lutas na perspectiva da cultura corporal. Conexões [Internet]. $27^{\circ}$ de março de 2013 [citado $10^{\circ}$ de abril de 2021];11(1):144-70. Disp. em: https://periodicos.sbu.unicamp.br/ojs/in dex.php/conexoes/article/view/8637635

2. Ferreira HS. As Lutas na Educação Física Escolar. Revista de Educação Física / Journal of Physical Education [Internet]. 1 [citado $10^{\circ}$ de abril de 2021];75(135). Disponível em: https://revistadeeducacaofisica.emnuven s.com.br/revista/article/view/428

3. Darido SC; Rangel ICA. Educação Física na escola: implicações para a prática pedagógica. 2a Ed. Rio de Janeiro: Guanabara Koogan, 2019. p. 244- 261.

4. Rufino LGB; Darido SC. O Ensino das Lutas na Escola: possibilidades para a Educação Física. $1^{\mathrm{a}}$ ed. Porto Alegre. Ed Penso; 2015.

5. Gomes MSP. O Ensino do saber lutar na universidade: estudo da didática clínica nas Lutas e esportes de combate. [Faculdade de Educação Física] Universidade Estadual de Campinas; 2014. Disponível em: http://repositorio.unicamp.br/jspui/handl e/REPOSIP/275054

6. Lançanova JES. Lutas na Educação Física Escolar: alternativas pedagógicas. [Faculdade de Educação Física] Universidade da Região da Campanha; 2006. Disponível em: https://docplayer.com.br/3067467Lutas-na-educacao-fisica-escolaralternativas-pedagogicas-jader-emilioda-silveira-lancanova-resumo.html

7. Brasil. Diretoria de Educação Preparatória e Assistencial (DEPA). Caderno de Didática do Sistema Colégio Militar do Brasil. 2020; 1:1-42. Disponível em: http://www.depa.eb.mil.br/images/secs/ ensino/caderno_de_ditatico.pdf 
8. Cervo LA; Bervian PA. Metodologia Científica. $1^{\text {a }}$ Ed. São Paulo: Makron Books do Brasil, 1996.

9. Gil AC. Como elaborar Projetos de

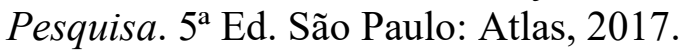

10. Baruch Y. Response Rate in Academic Studies - A Comparative Analysis. Human Relations. [Online] 1999;52(4): 421-438. Available from: doi:10.1023/A:1016905407491

11. BRASIL. Instituto Brasileiro de Geografia e Estatística (IBGE). Pesquisa Nacional por Amostragem de Domicílio (PNAD). 2017. Disponível em: http://www.ibge.gov.br

12. Andrade Neto JB. Efeitos Fisiológicos do Treinamento Físico de Krav Maga nas variáveis: hemodinâmica, metabólica, hidratação, neuromuscular, hormonal e sono. [Mestrado em Saúde do Adulto]. Universidade Federal do Maranhão; 2019. Disponível em: https://sigaa.ufma.br/sigaa/public/progra $\mathrm{ma} /$ apresentacaostricto.jsf?lc $=\mathrm{ptBRidP}$ rograma $=962$

13. Preyer CT. Educação física escolar: a importância da diversificação no ensino de seus conteúdos. [Faculdade de Educação Física]; 2000. Disponível em: $<$ www.bibliotecadigital.unicamp.br/doc ument $/$ ?view $=000330320>$.

14. Antunes MM; Almeida JJG. Artes Marciais, Lutas e esportes de combate na perspectiva da Educação Física reflexões e possibilidade. vol $1.1^{\mathrm{a}}$ ed. Curitiba CRV. 2015.

15. Drigo AJ; Neto SS; Cesana J; Tojal, JBA. Artes marciais, formação profissional e escolas de ofício: Análise documental do judô brasileiro. Motricidade. 2011. vol. 7, n. 4, p. 49-62.

16. BRASIL. Base Nacional Comum Curricular (BNCC). Educação é a Base. Brasília, MEC/CONSED/UNDIME, 2017. Disponível em: http://www.mec.gov.br 